\title{
Neurobehavioral performance of Inuit children with increased prenatal exposure to methylmercury
}

\section{Citation}

Weihe, Pál, Jens C. Hansen, Katsuyuki Murata, Frodi Debes, Poul J. Jørgensen, Ulrike Steuerwald, Roberta F. White, and Philippe Grandjean. "Neurobehavioral performance of Inuit children with increased prenatal exposure to methylmercury." International Journal of Circumpolar Health 61, no. 1 (2002): 41-49. doi: 10.3402/ijch.v61i0.17404

\section{Published Version}

http://dx.doi.org/10.3402/ijch.v61i0.17404

\section{Permanent link}

http://nrs.harvard.edu/urn-3:HUL.InstRepos:34787293

\section{Terms of Use}

This article was downloaded from Harvard University's DASH repository, and is made available under the terms and conditions applicable to Other Posted Material, as set forth at http:// nrs.harvard.edu/urn-3:HUL.InstRepos:dash.current.terms-of-use\#LAA

\section{Share Your Story}

The Harvard community has made this article openly available.

Please share how this access benefits you. Submit a story.

Accessibility 


\section{NEUROBEHAVIORAL PERFORMANCE OF INUIT CHILDREN WITH INCREASED PRE- NATAL EXPOSURETO METHYLMERCURY}

\begin{abstract}
Exposure to methylmercury from marine mammals and other seafood may affect the development of the central nervous system. In a traditional Inuit community in Qaanaaq, Greenland, mercury concentrations in cord blood and maternal hair have been examined in connection with all births. We examined 43 children at age 7-12 years with a battery of neurobehavioral tests. The average mercury concentration in hair was $5.0 \mu \mathrm{g} / \mathrm{g}$ and $15.5 \mu \mathrm{g} / \mathrm{g}$ in children and mothers, respectively. Clinical neurological examination did not reveal any obvious deficits. However, neuropsychological tests showed possible exposure-associated deficits, though only in a few cases reaching statistical significance. In conjunction with data from other studies, peak latencies on brainstem auditory evoked potentials tended to be prolonged at increased exposure levels. The data from the present study therefore appears in accordance with other evidence that prenatal or early postnatal exposures to methylmercury may cause subtle neurobehavioral deficits. (Int J Circumpolar Health 2002; 61: 41-49)
\end{abstract}

Methylmercury can have serious adverse effects on the development and functioning of the human central nervous system, especially when exposure occurs prenatally or during childhood ( $1-3)$. In serious prenatal methylmercury poisoning, neuropathological studies have shown diffuse brain damage (4-6). Subtle neurological or neuropsychological effects have been reported at lower exposure levels in some, though not all, studies using sensitive outcome measures (7-10). Although the risk of damage to the fetal brain seems to be greater when maternal hair-mercury concentrations exceed $10 \mu \mathrm{g} / \mathrm{g}$ (3), the safe level of exposure has not yet been determined with any certainty. This issue is of substantial public health relevance in populations relying on seafood contaminated with methylmer-

\author{
Pál Weihe, ${ }^{1,2}$ Jens $C$. \\ Hansen, ${ }^{3}$ Katsuyuki \\ Murata, ${ }^{4}$ Frodi Debes, ${ }^{1}$ \\ Poul J. Jørgensen, ${ }^{5}$ Ulrike \\ Steuerwald, ${ }^{1}$ Roberta F. \\ White, ${ }^{2,6}$ and Philippe \\ Grandjean ${ }^{2,6}$
}

'Department of Occupational and Public Health, The Faroese Hospital System, Torshavn, Faroe Islands; ${ }^{2}$ Department of Environmental Medicine, Odense Univer-

sity, Odense, Denmark; ${ }^{3}$ Department of Environmental and Occupational Medicine, Aarhus University, Aarhus, Denmark; ${ }^{4}$ Department of Public Health, Faculty of Medicine, University of Tokyo, Tokyo, Japan; ${ }^{5}$ Institute of Clinical Research,

Odense University Hospital, Odense, Denmark; and 'Departments of Neurology and Environmental Health, Schools of Medicine and Public Health, Boston University, Boston, MA, USA. 


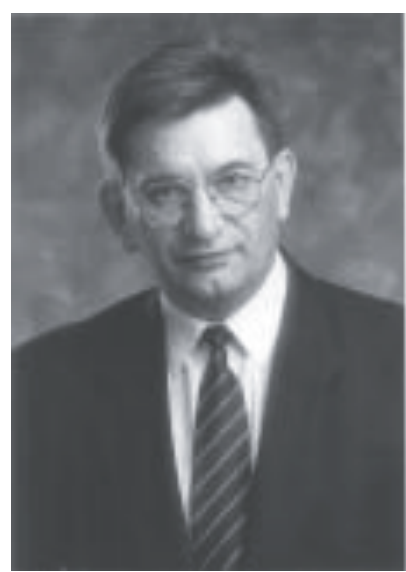

Pál Weihe, born 1949, MD, Chief Physician, Department of Occupational and Public Health in the Faroe Islands. Since 1985 epidemiological studies on the impact of polluted seafood on children's health and development. cury.

Marine mammals tend to accumulate methylmercury, and average concentrations of about $0.5-1.0 \mu \mathrm{g} / \mathrm{g}$ wet weight have been reported for muscle tissue of narwhal and beluga ( I I). The current Provisional Tolerable Weekly Intake for methylmercury of $0.2 \mathrm{mg}$ (3) would then be exceeded by a daily intake of 30-60 g of whale meat. Accordingly, a hair-mercury concentration of $10 \mu \mathrm{g} / \mathrm{g}$ is often exceeded in arctic communities, and so is the corresponding limit of $50 \mu \mathrm{g} / \mathrm{l}$ blood $(12,13)$. Monitoring of cordblood mercury concentrations has been continued in Qaanaaq, the northernmost Inuit community in Greenland, for more than a decade (14). With the high exposures documented during the last 15 years, a small group of highly-exposed Inuit children was examined to provide information on the effects of high exposures and the possible difference in susceptibility between children with different genetic backgrounds.

\section{SUBJECTS AND METHODS}

Subjects

Data from Aarhus University on mercury in maternal blood and umbilical cord blood from births in Thule were available from 1982 and onwards (14). Although the population is small, a total of 40 children less than 12 years of age were thought to be potentially available for the study. The District Medical Officer assisted in identifying and contacting the families. Several families had moved away from the district, and others, though remaining in the district, lived too far away to be able to travel to the examinations within a reasonable time. We managed to examine 21 of these children, i.e., slightly more than half of the eligible population. In addition, 22 other children aged 7-12 years, and residing in the same community, were examined.

\section{METHODS}

A pediatrician carried out a thorough physical examination that included a functional neurological examination with emphasis on motor coordination and perceptualmotor performance $(9,16)$. The mother filled in a questionnaire with social and general health information. 
Neurobehavioral tests were selected to provide some comparison points to the studies carried out in the Faroe Islands (9) and Madeira (16) and to minimize the influence of cultural differences and translation on the performance. An interpreter was used for the administration of all tests. The tasks chosen were considered likely to be feasible in this testing situation. The tests also had to be acceptable to the children and their parents, viz. painless and not too time-consuming, and appropriate for Inuit children in the age range of 6- 12 years. The same psychologist administered the paper-and-pencil tests as in the Faroes and Madeira, in the latter locality with the help of local interpreters.

Three computer-assisted neuropsychological tests were used from the Neurobehavioural Evaluation System (NES2) $(9,17,18)$. Finger Tapping was completed for $15 \mathrm{~s}$ each with the preferred hand, the nonpreferred hand, and with both hands. Score was the maximum number of taps achieved in two trials for each condition. In the Hand-Eye Coordination Test, the child had to follow a sine-wave curve on the computer screen using a joy stick. Score was average deviation from the stimulus in the best two trials. In the Continuous Performance Test, the children watched a series of animal silhouettes flashed on the computer screen, and the child was required to press a button every time a cat appeared over a 4-min interval. Scores were the total number of missed responses and the average reaction time. Two translated Wechsler Intelligence Scale for Children-Revised (WISC-R) subtests were used (19): Digit Spans and Block Designs. We supplemented this battery with a translated version of the Stanford-Binet Bead Memory test (20), where the child was asked to replicate designs made of beads.

Neurophysiological examination was carried out with a four-channel electromyograph (Medelec Sapphire-4ME) and included brainstem auditory evoked potential (BAEP) and visual evoked potential (VEP) latencies. BAEP were recorded in subjects who were lying comfortably $(9,21,22)$. Click signals with intensity of $65 \mathrm{~dB} \mathrm{HL}$ (0.I msec impulses of alternating polarity) were presented to the right ear through electromagnetically shielded earphones at rates of 20 and $40 \mathrm{~Hz}$. Recording was through three standard electroencephalographic electrodes placed on the vertex, right mastoid ipsilateral to stimulation and left mastoid (ground). The I, III and V peaks of the BAEP are thought to 
reflect the volume-conducted electric activity from the acoustic nerve, pons and midbrain in the auditory pathway, respectively (2I). Pattern-reversal VEP with binocular fullfield stimulation was conducted in a darkened room ( 9 , $22,23)$. Subjects sat quietly $127 \mathrm{~cm}$ in front of a 17 -inch TV screen and were asked to watch the centre of the screen. The checkerboard pattern on the TV screen consisted of white and black squares, reversing at a rate of $2 / \mathrm{sec}$. Two kinds of checks were used (arc widths of 30' and I 5'). One positive and two negative peaks (PI00, N75 and NI45) were recorded using standard EEG electrodes fixed to the occipital cortex, the forehead and the left mastoid (ground).

Cord-blood mercury concentrations were available from all children born in Thule (14). For assessment of current exposure, a hair sample was collected from all children as well as from their mothers, and the first c. $2 \mathrm{~cm}$ closest to the root were analyzed. Mercury analysis was carried out by microwave digestion followed by flow-injection cold-vapour atomic absorption spectrometry $(9,24)$. The results may be converted to SI units, where 1.0 $\mu \mathrm{g}=5.0 \mathrm{nmol}$. The clinical staff had no information on the exposure data.

As the distributions of mercury concentrations were highly skewed, logarithmic transformations were used in multiple regression analyses. The approach was similar to the one used in the previous study in the Faroe Islands (9). The different sets of mercury concentrations were entered as an independent variable in separate equations where adjustment was made for age, sex, presence of older siblings at home, younger siblings, and, for the computer-assisted tests, level of acquaintance with computers.

Joint analyses were also undertaken using previously published results from the Faroe Islands $(9,25)$ and Madeira (16), where mercury exposures are less. However, as social and environmental confounder variables may not act the same way in the different study locations, only evoked potential latencies were used in these analyses. Children with glasses were excluded from the VEP data, and those with current middle ear infection from the BAEP calculations.

\section{RESULTS}

Of the children examined, 24 were boys and 19 were girls. 
The age varied between 6.2 and 12.0 years, with a median of 8.4 years. Cord-blood mercury concentrations $(\mathrm{N}=$ 21) varied from $28 \mu \mathrm{g} / \mathrm{l}$ to $777 \mu \mathrm{g} / \mathrm{l}$, (geometric mean, 93 $\mu \mathrm{g} / \mathrm{l}$.). The children's hair mercury concentrations $(\mathrm{N}=43)$ varied up to $18.4 \mu \mathrm{g} / \mathrm{g}$ (geometric mean, $5.5 \mu \mathrm{g} / \mathrm{g}$ ). The 3 | maternal hair samples showed a maximum mercury concentration of $32.9 \mu \mathrm{g} / \mathrm{g}$ geometric mean, $15.5 \mu \mathrm{g} / \mathrm{g}$ ). The associations between the three mercury exposure parameters failed to reach statistical significance, the best correlation being between the two current hair mercury parameters. This finding suggests that, in this community, mercury exposure may vary over time, and that the mercury concentrations may only be indicators of relative magnitudes of long-term exposure levels.

The mercury concentrations were not associated with the age or sex of the child and sociodemographic parameters mentioned in Table I. However, the hair-mercury concentrations increased significantly with the number of weekly dinners with traditional food, especially in the children $(r=0.33)$.

Upon physical examination, the children included in the study generally appeared well, and none of them showed any overt indication of being affected by mercury. As expected for this age group, most of the children performed optimally on the functional neurological tasks, and questionable or poor performance was more frequent in the youngest children. No neurological disease of other origin was found.

Neuropsychological examinations with the interpreter were carried out as scheduled (Table II). As these children were up to 12 years old, it was not surprising that most of them (30/43) had at least some acquaintance with computer games. After adjustment for this factor as well as age and sex, reaction time appeared to increase with increas-

Table I. Characteristics of 43 children from Qaanaaq, Greenland, examined for mercury-associated neurobehavioral deficits.

\begin{tabular}{ll}
\hline Parameter & Number \\
\hline Fish dinners per week $(0-\mathrm{I} / \geq 2)$ & $31 / 9$ \\
Seal/whale dinners per week $(0-I / \geq 2)$ & $21 / 19$ \\
Western dinners per week $(0-4 / \geq 5)$ & $17 / 23$ \\
Mother employed (yes / no) & $31 / 12$ \\
Father employed (yes / no) & $30 / 13$ \\
Child's computer acquaintance (yes / no) & $30 / 13$ \\
Number of household members $(\leq 5 />5)$ & $27 / 12$ \\
Older siblings at home (yes / no) & $26 / 17$ \\
Younger siblings at home (yes / no) & $30 / 13$ \\
\hline
\end{tabular}


Table II. Results of neuropsychological tests in 43 Inuit children exposed to methylmercury from seafood

\begin{tabular}{lccc}
\hline Test & $N$ & Mean & Range \\
\hline $\begin{array}{l}\text { NES2-Finger Tapping (maximum in I5 s) } \\
\text { Preferred hand }\end{array}$ & 43 & 49.7 & $33-66$ \\
Other hand & 43 & 46.7 & $28-62$ \\
Both hands & 42 & 73.3 & $48-94$ \\
NES2-Hand-Eye Coordination (average of best two trials) & 43 & 2.42 & $1.60-3.16$ \\
Error score & 43 & & $0-14$ \\
NES2-Continuous Performance Test & 43 & 3.16 & $505-916$ \\
Total missed responses & 695 & $1-6$ \\
Average reaction time (ms) & 40 & 2.8 & $0-6$ \\
Wechsler Intelligence Scale for Children-Revised & 2.3 & $4-43$ \\
Digit Spans, forward & 40 & 18.9 & $7-30$ \\
backward & 40 & & 16.6 \\
Block Designs & 40 & & \\
Stanford-Binet & 40 & & \\
Bead Memory & & & \\
\end{tabular}

ing mercury exposure level, particularly as indicated by the cord-blood mercury concentration $\left(r_{s}=0.34, p=0.13\right)$. The number of missed responses on the CPT also seemed to increase slightly with increasing exposure. Performance on the hand-eye coordination measure (an error score) was positively associated with mercury exposure, especially the maternal hair mercury concentration $\left(r_{s}=0.44, p=\right.$ 0.01 ). These associations did not seem to be affected by known confounding factors. The paper-and-pencil tests tended to show small deficits at increasing mercury exposure levels, but none was statistically significant.

The results may be compared with those obtained by a larger group of 7-year-old Faroese children (9). The older Inuit children performed better on the computerized tests, especially finger tapping, reaction time, and hand-eye coordination. The results on the Digit Span forward condition were similar to those seen on the Faroes, despite the difference in age, but the average score on Block Design was significantly better than in the Faroes (9). The Bead Memory test was not used in the Faroes, but the average in Thule was clearly better than the averages about 14 obtained in 7-year-old children on Madeira (16) and in 7-to12-year-old children from the Brazilian Amazon (26).

Evoked potentials were recorded in 40 children (Table III). As anticipated (9), sex seemed an important predictor for several latencies, although it did not reach statistical significance, while age appeared not to have any clear effect. The I-III interval on the BAEP and the NI45 latency on the VEP were adjusted for these two covariates. Mercury exposure as indicated by the maternal hair-mercury 
Table III. Mean \pm s.d. for latencies (ms) of evoked potentials thought to be related to mercury exposure, as recorded in 40 Inuit children in comparison with results from two other studies, with the joint regression coefficient for the logarithmic transformation of the maternal hairmercury concentration.

\begin{tabular}{|c|c|c|c|c|c|}
\hline Test & & $\begin{array}{l}\text { Thule } \\
(n=40)\end{array}$ & $\begin{array}{l}\text { Madeira } \\
(n=149)\end{array}$ & $\begin{array}{l}\text { Faroes } \\
(n=440)\end{array}$ & $\begin{array}{l}\text { Regression } \\
\text { coefficient } \\
\text { for mercury }\end{array}$ \\
\hline \multicolumn{6}{|c|}{ Brainstem Auditory Evoked Potential latencies ${ }^{a}$} \\
\hline \multirow[t]{3}{*}{$20 \mathrm{~Hz}:$} & $\mathrm{I}-\mathrm{III}$ & $2.10 \pm 0.27$ & $2.12 \pm 0.22$ & $2.19 \pm 0.31 *$ & $0.10^{+t}$ \\
\hline & III-V & $1.97 \pm 0,26$ & $1.85 \pm 0.17^{*}$ & $1.85 \pm 0.24 *$ & 0.02 \\
\hline & $\mathrm{I}-\mathrm{V}$ & $4.07 \pm 0.31$ & $3.97 \pm 0.23$ & $4.05 \pm 0.31$ & $0.08^{\dagger}$ \\
\hline \multirow[t]{3}{*}{$40 \mathrm{~Hz}:$} & $\mathrm{I}-\mathrm{III}$ & $2.23 \pm 0.31$ & $2.19 \pm 0.28$ & $2.29 \pm 0, .35^{*}$ & $0.1 \mathrm{I}^{\dagger}$ \\
\hline & III-V & $1.97 \pm 0.23$ & $1.94 \pm 0.22$ & $1.87 \pm 0.28$ & 0.03 \\
\hline & $\mathrm{I}-\mathrm{V}$ & $4.20 \pm 0.35$ & $4.12 \pm 0.28$ & $4.16 \pm 0.35$ & $0.08^{\dagger}$ \\
\hline \multicolumn{6}{|c|}{ Visual Evoked Potential latencies ${ }^{b}$} \\
\hline 30': & NI45 & $151.6 \pm 12.2$ & $143.7 \pm 11.6^{*}$ & $140.4 \pm 13.2^{*}$ & -2.2 \\
\hline I5': & NI45 & $153.2 \pm 9.7$ & $150.4 \pm 12.7$ & $145.2 \pm 12.2^{*}$ & 0.7 \\
\hline
\end{tabular}

after exclusion of children with middle ear infection on the right side bafter exclusion of children using glasses

*different from the Inuit group $(p<0.05)$ after adjustment for age and sex ${ }^{\dagger} \mathrm{p}<0.05$ and ${ }^{\dagger} \mathrm{p}<0.01$

concentration was associated with the greatest relative increases of the NI45 latency on the 30' pattern, but statistical significance was not reached due to the small number of observations.

As evoked potentials are not known to be affected by confounders other than sex and age, the latencies thought to be delayed at increased mercury exposure levels were compared between the three study locations (Table III). For the BAEP III-V interpeak latency at $40 \mathrm{~Hz}$ and the VEP NI45 latencies, there appears to be an increased delay from the lowest exposure group in the Faroes $(9,25)$ via Madeira (I6) to the highest levels in Greenland (Table III). However, these tendencies may be affected by community differences other than mercury exposure.

The maternal hair-mercury concentration was then used as the joint exposure variable, as it was determined at all three study locations, i.e., at the time of examination in the present study and in Madeira, and at the time of parturition in the Faroese study. Dummy parameters for Madei$\mathrm{ra}$ and the Faroes were also included to account for any differences related to the recording circumstances, genetic background, etc. Mercury was found to be a significant predictor for the latencies of the BAEP I-III and I-V intervals in these analyses (Table III). The limited number of cord-blood analyses from the present study did not allow any detailed analyses of this predictor.

\section{REFERENCES}

1. Kurland LT, Faro SN, Siedler H. Minamata disease: the outbreak of a neurologic disorder in Minamata, Japan, and its relationship to the ingestion of seafood contaminated by mercuric compounds. World Neurol 1959; 1: 370-95.

2. Igata A. Epidemiological and clinical features of Minamata disease. Environ Res 1993; 63: 157-69.

3. WHO. Methylmercury (Environmental Health Criteria 101). WHO, Geneva, 1990

4. Takeuchi T, Morikawa N, Matsumoto H, Shiraishi Y. A pathological study of Minamata disease in Japan. Acta Neuropathologica 1962; 2: 40-57.

5. Matsumoto H, Koya G, Takeuchi, T. Fetal Minamata disease: a neuropathological study of two cases of intrauterine intoxication by a methyl mercury compound. J Neuropathol Exp Neurol 1965; 24: 563-74.

6. Choi BH. The effects of methylmercury on the developing brain. Progr Neurobiol 1989; 32: 447-70.

7. McKeown-Eyssen GE, Buedy J, Neims A. Methyl mercury exposure in northen Quebec: II. Neurologic findings in children. Am J Epidemiol 1983; 118: 470-9.

8. Kjellström T, Kennedy P, Wallis S. Physical and mental development of children with prenatal exposure to mercury from fish. Stage 2 , interviews and psychological tests at age 6 . (Report 3642) Stockholm: National Swedish 
Environmental Protection Board, 1989.

9. Grandjean P, Weihe P, White RF, Debes F, Araki S, Murata K, Sørensen N, Dahl D, Yokoyama K, Jørgensen PJ. Cognitive deficit in 7-year-old children with prenatal exposure to methylmercury. Neurotoxicol Teratol 1997; 19: 417-28.

10. Davidson PW, Myers G, Cox C et al. Longitudinal neurodevelopmental study of Seychellois children following in utero exposure to methylmercury from a maternal fish ingestion: outcomes at 19 and 29 months. Neurotoxicol 1995; 16: 677-88.

11. AMAP Assessment Report. Arctic Pollution Issues. Oslo: Arctic Monitoring and Assessment Program, 1998.

12. Hansen JC, Sloth Pedersen H. Environmental exposure to heavy metals in northern Grenland. Arct Med Res 1986; 41: 21-34.

13. Hansen JC. Human exposure to metals through consumption of marine foods: a case study of exceptionally high intake among Greenlanders. In: Furness RW, Rainbow PS, eds. Heavy metals in the marine environment. Boca Raton, FL: CRC, 1990: 227-43.

14. Hansen JC, Tarp U, Bohn J. Prenatal exposure to methylmercury among Greenlandic Polar Inuits. Arch Environ Health 1990; 45: 355-8.

15. Lier L, Michelsen N. Fumlere og tumlere. (Publikation 10) Copenhagen: Institut for social medicin, 1984.

16. Murata K, Weihe P, Renzoni A, Debes F, Vasconcelos R, Zino F, Araki S, Jørgensen PJ, White RF, Grandjean P. Delayed evoked potentials in Madeiran children exposed to methylmercury from seafood. Neurotoxicol Teratol 1999; 21:343-8.

17. Letz R, Baker EL. NES2, neurobehavioral evaluation system manual. Winchester, MA: Neurobehavioral Systems, 1988.

18. Dahl R, White RF, Weihe P, Sørensen N, Letz R, Hudnell K, Otto DA, Grandjean P. Feasibility and validity of three computerassisted neurobehavioral tests in 7-Year old children. Neurotoxicol Teratol 1996; 18: 4139.

19. Wechsler D. Wechsler intelligence scale for children-revised. New York: Psychological Corp., 1974.

20. Thorndike RL, Hagen EP, Sattler JM. Stanford-Binet Intelligence Scale, 4th edition. Chicago: The Riverside Publishing Company, 1986.

21. Stockard JJ, Stockard JE, Sharbrough FW. Brainstem auditory evoked potentials in neurology: Methodology, interpretation, and clinical application. In "Electrodiagnosis in Clinical Neurology” (Aminoff MJ, ed.), 2nd ed. Churcill Livingstone, New York, 1986, pp.

\section{DISCUSSION}

This small study deals with a population with very high exposures to methylmercury from their seafood diet, including marine mammals. Because of the small size of the group examined, the statistical power of this study is limited. However, it is noteworthy that the children who participated in the examinations did not appear to be clinically adversely affected by the exposure.

Methylmercury poisoning is known to cause neurological abnormalities, including delayed evoked potentials and peripheral nerve conduction velocities (2), as well as morphological changes in the brain (4-6). Evoked potentials were recorded by the same methods and the same examiner as in the study of Faroese children, where detailed information on prenatal methylmercury exposures from seafood was available (9). Significant delays in BAEP latencies were seen in the Faroese children, and this finding seemed to be in accordance with the results of the present study. However, the present study is too small to allow an independent evaluation of this hypothesis.

The neuropsychological tests failed in revealing clear mercury-related deficits. At the same time, some predictors that would be expected to affect the performance, such as computer acquaintance, age and sex, also did not show any significant relation with the results. The larger group of Faroese children showed several mercury-associated deficits in similar tests (9). However, the use of an interpreter, the wide age range of the children examined, and the general cultural and social circumstances may have affected the performance. These factors may have prevented otherwise important predictors from reaching statistical significance. However, both the reaction time measure and the number of missed responses showed an exposure-association similar to the one seen in the Faroese children. Thus, the absence of a statistically significant relationship to the neurotoxicant exposure in this study is not necessarily an indication that no adverse effect has occurred.

The mercury exposures documented in this study are comparatively high. Thus, although the geometric average of the children's own hair-mercury concentrations was only slightly higher than in the Faroes, the maternal average was about three-fold higher than the Faroese level. 
Previous studies (7-10) also mainly regard methylmercury exposures at lower average levels. Based on the maternal hair-mercury concentrations, this Inuit population would therefore be considered to be of particular risk of methylmercury toxicity.

While clinical deficits were not documented, risk assessment must take into account the benefits of the traditional diet and its role in Inuit culture (II). However, the wide dispersal of marine pollution and its accumulation in arctic mammals have created a situation which may constitute a risk to both human health and a unique culture. The findings of the present study would suggest that preventive efforts against marine pollution need further attention.

\section{Acknowledgments}

This study was supported by grants from the European Commission Environment Research Programme and the Danish Medical Research Council. We thank Dr. Kazuhito Yokoyama for technical support and Chief Medical Officer Bent Jørgensen and the staff at the Qaanaaq Hospital for their assistance.
467-503.

22. Murata K, Araki S, Yokoyama K, Nomiyama K, Nomiyama H, Tao Y-X, Liu S-J. Autonomic and central nervous system effects of lead in female glass workers in China. Am J Ind Med 1995; 28: 233-44.

23. Sokol, S. Visual evoked potentials. In "Electrodiagnosis in Clinical Neurology" (Aminoff MJ, ed.), 2nd ed. Churchill Livingstone, New York, 1986, pp. 441-66.

24. Pineau A, Piron M, Boiteau H-L, Etourneau M-J, Guillard O. Determination of total mercury in human hair samples by cold vapor atomic absorption spectrometry. J. Anal. Toxicol. 1990; 14: 235-8.

25. Murata K, Weihe P, Araki S, Budtz-Jørgensen E, Grandjean P. Evoked potentials in Faroese children prenatally exposed to methylmercury. Neurotoxicol Teratol 1999; 21: 471 2.

26. Grandjean P, White RF, Nielsen A, Cleary D, de Oliveira Santos EC. Mercury neurotoxicity in Amazonian children downstream from gold mining. Environ Health Perspect 1999; 107: 587-91

Philippe Grandjean, MD

Department of Environmental Medicine

Odense University, Winsløwparken 17

DK-5000 Odense, Denmark

Tel. $+45-6550.3769$

Fax: $+45-6591-1458$

Email:pgrandjean@health.sdu.dk 